\title{
Behavioural mechanisms underlying functional response of sea stars Asterias vulgaris preying on juvenile sea scallops Placopecten magellanicus
}

\author{
Melisa C. Wong ${ }^{1, *}$, Myriam A. Barbeau ${ }^{2}$, Michael Dowd ${ }^{3}$, K. R. Richard ${ }^{2}$ \\ ${ }^{1}$ Institute of Marine Sciences, University of North Carolina-Chapel Hill, Morehead City, North Carolina 28557, USA \\ ${ }^{2}$ Department of Biology, University of New Brunswick, Fredericton, New Brunswick E3B 1E6, Canada \\ ${ }^{3}$ Department of Mathematics and Statistics, Dalhousie University, Halifax, Nova Scotia B3H 3J5, Canada
}

\begin{abstract}
The functional response characterises the relationship between prey density and the consumption rate of individual predators. Typically, it is studied by fitting a model to observations of predation rate at different prey densities. The behavioural mechanisms underlying a functional response are not well understood, and estimates of model parameters seldom conform to observations of behaviour. We have developed a mechanistic approach that directly incorporates behavioural observations into characterisation of the functional response. Laboratory experiments were used to record predation rates and observe foraging behaviour of sea stars Asterias vulgaris preying on juvenile sea scallops Placopecten magellanicus at different densities. Experiments were conducted in tanks with no sediment and tanks with sediment. Behavioural data from the experiments were used to calculate parameters of functional response models $T_{h}$ (handling time per prey) and a (rate of successful search). On both substrates, $T_{h}$ remained constant across prey density, while $a$ was densitydependent. An inverse quadratic was used to describe a and was incorporated into a functional response model. Estimates of $a$ were also obtained by fitting the functional response model to the predation rate data using regression analysis. These estimates of a were highly consistent with the estimates calculated from behavioural data. On both substrates, sea stars preying on scallops had a Type III sigmoid-shaped functional response; on sediment, predation rate decreased at high prey densities. Sea star ability to capture attacked prey was probably the mechanism underlying the observed responses. In general, behavioural information can lead to better understanding of observed functional responses.
\end{abstract}

KEY WORDS: Functional response $\cdot$ Behavioural mechanisms $\cdot$ Rate of successful search $\cdot$ Handling time $\cdot$ Prey density $\cdot$ Sea scallop $\cdot$ Placopecten magellanicus $\cdot$ Sea star $\cdot$ Asterias vulgaris $\cdot$ Sediment

\section{INTRODUCTION}

The functional response has long been recognised as an important concept in predation theory (Solomon 1949, Holling 1959, Hassell 1978, Abrams 1990, Turchin 2003). The functional response characterises the relationship between prey density and the consumption rate of individual predators. Its form depends on how a predator changes its behaviour at different prey densities (Hassell 1978), and may also be associated with the defence strategy used by prey against predators (Seitz et al. 2001). Moreover, the functional response has implications for population dynamics and food-chain processes, since it can play a stabilising or destabilising role (Hassell 1978, Taylor 1984, Turchin 2003, Gross et al. 2004). Despite its potential importance in structuring populations, the underlying behavioural mechanisms that determine the form of response are not well understood. Relatively few studies attempt to examine the component behaviours of observed functional responses (but see Holling 1966, Hassell et al. 1976, Spitze 1985, Eggleston 1990a, Streams 1994). In this study, we directly incorporated behavioural observations into the charac- 
terisation of the functional response of a marine benthic predator. This enabled a better understanding of how the actions of the predator and prey affect the relationship between predation rate and prey density.

There are 3 main types of functional response defined in the literature (Hassell 1978, Taylor 1984). The observed functional responses in this study were identified by focusing on features that distinguish the Type II and Type III responses. (We were not concerned with the Type I response in our predator-prey system.) In the Type II functional response, predation rate per predator increases at a decelerating rate as prey density increases, and reaches a plateau at high prey densities. In contrast, the Type III response is a sigmoid curve, in which predation rate increases at an accelerating rate at low prey densities and then at a decelerating rate to a plateau at high prey densities. The response types are further distinguished by the different effects of prey density on proportional mortality (i.e., per capita mortality rate). In the Type II response, proportional mortality for the prey is inversely density-dependent, and can have destabilising effects on populations that cause localised prey extinction. The Type III response is positively densitydependent at low prey densities and inversely densitydependent at high prey densities, promoting refuges for prey at low prey density. Thus, the Type III response can have stabilising effects on populations.

In functional response models, the particular predator and prey behaviours important for determining the type of functional response are embodied in 2 parameters (Hassell 1978). These parameters are handling time per prey $T_{\mathrm{h}}$ and rate of successful search $a . T_{\mathrm{h}}$ comprises the time a predator spends handling 1 prey item, while a depends on the ability of a predator to encounter, attack and capture prey. $T_{\mathrm{h}}$ and $a$ do not vary with prey density in the Type II response, but one or both vary in the Type III response (Hassell 1978, Streams 1994). In most functional response studies, parameter values are usually estimated from regression analysis where models are fit to observations of predation rates over a range of prey densities (Juliano 2001). A limitation of this approach is that estimated parameter values seldom conform to direct observations of behaviour (e.g., Hassell 1978, Spitze 1985, Eggleston 1990a). The role specific predator or prey behaviours play in the observed functional response have seldom been examined.

In this paper, we directly link behavioural information to functional response models, using predatorprey interactions between sea stars Asterias vulgaris and juvenile sea scallops Placopecten magellanicus as our study system. Predation by sea stars is an important process that affects the abundance of juvenile sea scallops on the NW Atlantic coast (Barbeau et al. 1994,
Hatcher et al. 1996, Cliche et al. 2004, Wong et al. 2005). Previous research in the laboratory and field has shown that sea star predation of juvenile sea scallops is dependent on prey density (Barbeau et al. 1994, 1998, Wong \& Barbeau 2003, Wong et al. 2005). Also the predation rate of sea stars on small scallops is affected by the particle size of the sediment (Wong \& Barbeau 2003), and thus the substrate has the potential to affect the functional response of sea stars. Such substrate effect has been observed in another invertebrate predator-bivalve system (Lipcius \& Hines 1986). In nature, A. vulgaris and sea scallops are found on a variety of sediments, ranging from mud to boulderstrewn gravel (0.06 $\mu \mathrm{m}$ to $1024 \mathrm{~mm}$ diameter) (Stokesbury \& Himmelman 1995, Himmelman \& Dutil 1991). Sea stars are nonvisual, relatively slow-moving predators that locate prey using chemosensory detection (Sloan 1980). Scallops detect predators using chemosensory and visual detection, as they have sensory tentacles and image-forming eyes lining the mantle edge (Land 1984, Beninger \& le Pennec 1991). When an encounter occurs between a sea star and juvenile sea scallop, the scallop usually employs active escape (swimming or jumping) to evade capture (Barbeau \& Scheibling 1994, Wong \& Barbeau 2005). Juvenile sea scallops between $\sim 12$ and $70 \mathrm{~mm}$ shell height are effective swimmers (Dadswell \& Weihs 1990, Manuel \& Dadswell 1993). We used this sea star-scallop system as our study system since it is amenable to detailed behavioural analysis in the laboratory owing to the relatively slow movement velocity and long prey-handling time of sea stars (Barbeau \& Scheibling 1994, Wong \& Barbeau 2005).

Using juvenile sea scallops Placopecten magellanicus and predatory sea stars Asterias vulgaris, our general objectives were to (1) calculate parameter values in the functional response models using data from behavioural observations, (2) compare these calculated parameter values to those estimated using predation rate data (i.e., from fitting the functional response model), and (3) identify the important behavioural mechanisms underlying the observed functional response, by determining how parameter values and their behavioural components vary with prey density. Our objectives specific to the sea star-scallop system were to (4) determine the type of functional response displayed by sea stars preying on juvenile sea scallops, and (5) determine the effect of substrate heterogeneity on the observed functional responses. Generally, our mechanistic analysis is valuable for explicitly understanding how various behaviours of the predator and prey translate into the model. This conceptual framework, being grounded on careful empirical observations, may better explain and clarify the observed functional response. 


\section{MATERIALS AND METHODS}

Experimental animals. We conducted 2 experiments to study the functional response and underlying behaviour of sea stars Asterias vulgaris preying on juvenile sea scallops Placopecten magellanicus, at Huntsman Marine Science Centre, St. Andrews, New Brunswick, Canada. In Expt 1, glass tanks ( $30 \mathrm{~cm}$ wide $\times 30 \mathrm{~cm}$ high $\times 60 \mathrm{~cm}$ long) with flow-through sea water regulated at 0.5 to $1.5 \mathrm{l} \mathrm{min}^{-1}$ were used. Tanks had either no sediment (i.e., bare bottom surface of the tank to represent a homogeneous, hard substrate) or sediment (composed of $29 \%$ pebble, $59 \%$ granule and $12 \%$ sand (Wentworth 1922, Wong \& Barbeau 2003), to represent a heterogeneous substrate). In Expt 2, circular fibreglass tanks $(120 \mathrm{~cm}$ diameter $\times 25 \mathrm{~cm}$ high) with seawater flow regulated at 1 to $31 \mathrm{~min}^{-1}$ were used. No sediment was on the bottom of the fibreglass tanks. In both experiments, the sea water was sand-filtered $(20 \mu \mathrm{m})$ and the light regime was $14 \mathrm{~h}$ light:10 h dark.

Sea stars with 5 intact arms were collected from Passamaquoddy Bay. They were kept in holding tanks for 1 to $8 \mathrm{wk}$ prior to an experiment and fed blue mussels Mytilus edulis or periwinkles Littorina littorea. Food was removed from the tanks $\sim 1 \mathrm{wk}$ prior to an experiment to standardize hunger levels. Sea star diameter was measured as the distance between the tip of an average-sized arm to the centre of the oral region, multiplied by 2 (Table 1 ).

Juvenile sea scallops were obtained from Sea Perfect Cultivated Products, Arichat, Nova Scotia, and kept in holding tanks for 2 to $10 \mathrm{~d}$ prior to an experiment. Prior to and during experiments, scallops were batch-fed algal paste for 30 to $60 \mathrm{~min}$ each day at an approximate concentration of $1.0 \times 10^{4} \mathrm{cells} \mathrm{m}^{-1}$ sea water (Hollet \& Dabinett 1989). Scallop shell height was measured as the distance between the middle of the dorsal hinge and the furthest ventral shell edge (Table 1).

Experimental design. Expt 1 used a randomised block design with replication. Single predators were

Table 1. Details of experiments conducted to investigate functional response and underlying behaviour of sea stars Asterias vulgaris preying on juvenile sea scallops Placopecten magellanicus. Expt 1 = high prey density, no sediment or sediment present; Expt 2 = low prey density, no sediment (see 'Materials and methods, Experimental design' for full details). $\mathrm{SH}$ : shell height (mean $\pm \mathrm{SD}$; temp: temperature (mean $\pm \mathrm{SD}$ ); Time: total time observed tank $^{-1}$

\begin{tabular}{|lccccc|}
\hline Expt & $\begin{array}{c}\text { Date } \\
(\mathrm{dd} / \mathrm{mm} / \mathrm{yy})\end{array}$ & $\begin{array}{c}\text { Scallop } \\
\mathrm{SH}(\mathrm{mm})\end{array}$ & $\begin{array}{c}\text { Sea star } \\
\text { diam. }(\mathrm{mm})\end{array}$ & $\begin{array}{c}\text { Water } \\
\text { temp. }\left({ }^{\circ} \mathrm{C}\right)\end{array}$ & $\begin{array}{c}\text { Time } \\
(\mathrm{min})\end{array}$ \\
\hline Expt 1 & & & & & \\
block 1 & $06 / 10 / 01-18 / 10 / 01$ & $18.1 \pm 4.3$ & $120-180$ & $12.1 \pm 0.2$ & 600 \\
block 2 & $23 / 10 / 01-03 / 11 / 01$ & $19.3 \pm 4.5$ & $110-160$ & $10.6 \pm 0.5$ & 600 \\
Expt 2 & $20 / 10 / 02-02 / 11 / 02$ & $16.2 \pm 2.9$ & $140-160$ & $11.0 \pm 1.7$ & 450 \\
\hline
\end{tabular}

placed into 80 tanks containing 1 of 10 levels of 2 to 20 prey (11 to 111 scallops $\mathrm{m}^{-2}$ ) and 1 of 2 substrates. The experimental blocks were 2 time periods ( 2 wk each), and within each block 2 replicates of each of the 20 different treatment combinations were randomly allocated to 40 tanks.

Inspection of the data from Expt 1 indicated that it would be useful to obtain data for very low prey densities in tanks with no sediment. Thus, in Expt 2, single predators were placed into larger fibreglass tanks containing no sediment, and offered 1 of 6 levels of 2 to 62 prey ( 2 to 56 scallops $\mathrm{m}^{-2}$ ). A complete randomised design was used, with 4 replicates of each density randomly allocated to 24 tanks; 2 of the density levels in

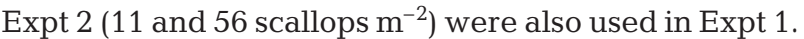

Natural mortality of prey was accounted for by maintaining control tanks that contained scallops with no predator (on no sediment and sediment). Expt 1 had 17 control tanks, each with 5 or 10 scallops; 1 tank with 12 scallops was used in Expt 2. No natural mortality occurred in either experiment.

Collection of predation data. In both experiments, each tank was monitored twice daily to record the number of scallops eaten. Consumed scallops were replaced to maintain prey densities at the prescribed levels. Predation rate was calculated for each sea star as the total number of scallops eaten divided by the number of days in the experiment. Proportional mortality in each tank was calculated as the number of scallops eaten divided by the number of scallops offered.

Collection of behavioural data. Throughout each Expt, predator and prey behaviour was observed in each tank during two 30 min observation periods per day (Table 1). The proportion of time engaged in a specific behaviour was calculated as the total duration of that behaviour divided by total observation time. Searching behaviour occurred when a sea star moved with sensory tentacles extended from curled arm-tips (Wong \& Barbeau 2003). Handling behaviour began when a sea star encountered a scallop and ended when the sea star avoided the scallop, the sea star consumed the scallop, or the scallop escaped. Handling time per prey was defined as the length of time between an encounter and the end of consumption; the time to avoid a scallop or time to handle a scallop that escaped were not included, since these times were very short. An encounter occurred when a sea star made physical contact with a scallop, or a scallop actively escaped from an approaching sea star. Outcomes of encounters were categorised as avoidance (the predator avoided the prey), pre-capture escape 
(the prey escaped before being captured), post-capture escape (the prey escaped after being captured), or consumption (the predator consumed the prey).

Effects of prey density on predation and behavioural data. Analyses of variance (ANOVA) were used to assess the effect of prey density on predation rate, proportional mortality and specific predator-prey behaviours. For Expt 1, mixed-model ANOVAs were used, with time-block as a random factor, and prey density and substrate as fixed factors. If interactions with block or if block itself were highly non-significant ( $p$ > 0.25), a partial mixed-model or a fixed-model ANOVA was conducted (Winer et al. 1992, Wong \& Barbeau 2003). Handling time per prey in Expt 1 was analysed using a nested ANOVA with multiple observations per tank. The factor 'tank' was nested in the interaction of prey density and substrate (data pooled across blocks). For Expt 2, the various measures of predation were analysed using a 1 way fixed model ANOVA. No analysis was done for handling time per prey in Expt 2, since there were few observations of sea stars handling prey to completion. For all analyses, Cochran's test was used to test the assumption of homogeneity of variances. When this assumption was violated, transformations such as square root and log $($ datum +1$)$ were used to obtain homogeneous variances. ANOVAs were performed on untransformed data in cases where this assumption could not be met, with awareness of increased probability of Type I error (Underwood 1997). Multiple comparisons were done with the Student-Newman-Keuls (SNK) test when there were $\leq 3$ means or when means were evenly spaced, and Ryan's $Q$-test when there were $>3$ means that were not evenly spaced (Day \& Quinn 1989, Underwood 1997).

Incorporation of behavioural data into predation model. A simple model for linking predation rate to the behaviours of predator and prey is:

$N_{\mathrm{e}}=E \cdot T_{\mathrm{S}} \cdot \operatorname{Pr}\{$ attack $\mid$ encounter $\} \cdot \operatorname{Pr}\{$ capture $\mid$ attack $\} \cdot$ Pr\{consumption|capture\}

where $N_{\mathrm{e}}$ is number of prey eaten per predator per unit time, $E$ is number of prey encountered per predator per time spent searching, $T_{\mathrm{s}}$ is the proportion of time a predator spends searching, and $\operatorname{Pr}\{\mathrm{A} \mid \mathrm{B}\}$ denotes the probability of behaviour A conditional on behaviour B having already occurred (O'Brien 1979, Wong \& Barbeau 2003). Behavioural data for each predator was used to calculate Pr\{attack|encounter\} as [(encounters-avoidances)/encounters], Pr\{capture| attack\} as [(post-capture escapes + consumptions)/ (encounters-avoidances)], and $\operatorname{Pr}$ \{consumption|capture\} as [consumptions/(post-capture escapes + consumptions)]. E was calculated in 2 ways: (1) as (encounters/searching time), and (2) from a genera- lised model of encounter rate, which assumes random movement of predator and prey in a 2 dimensional environment (Holling 1966, or see Wong 2004 for details). E calculated with the generalised model used a sea star velocity of $150 \mathrm{~cm} \mathrm{~h}^{-1}$ on no sediment, and $70 \mathrm{~cm} \mathrm{~h}^{-1}$ on sediment (based on video-observations from similar experiments: Barbeau \& Scheibling 1994, Barbeau et al. 1994). Scallop velocity used was $0 \mathrm{~cm}$ $\mathrm{h}^{-1}$, since scallops generally do not swim until physical contact with a sea star. Sea star radius was the average diameter divided by 2 , and scallop radius the average shell height divided by 2 .

Use of behavioural data to calculate parameters of functional response model. The predation rate model (Eq. 1) can be directly related to a functional response model. The classic model for functional response (Holling 1959) was first expressed as:

$$
N_{\mathrm{e}}=a T_{\mathrm{s}} N_{\mathrm{t}}
$$

where $a$ is the rate of successful search and $N_{\mathrm{t}}$ is prey density. Substituting Eq. (2) into Eq. (1) yields:

$$
a=\frac{E \cdot \operatorname{Pr}\{\text { consumption } \mid \text { encounter }\}}{N_{\mathrm{t}}}
$$

where Pr\{consumption|encounter\} is equivalent to the product of the 3 conditional probabilities in Eq. (1). From behavioural data, Pr\{consumption|encounter\} was calculated as (consumptions/encounters). Eq. (3) was used to calculate $a$, as some sea stars at low prey density failed to capture any scallops during the observation periods (resulting in undefined values for Pr\{consumption|capture\}).

Fitting of functional response model to predationrate data. The following analysis was undertaken to identify and fit an appropriate functional response model to the observed predation-rate data. For the parts of this analysis that describe the functional response on no sediment, data were pooled from both experiments in order to include information from very low prey densities. All analyses of the functional response on sediment were based on data obtained entirely from Expt 1.

Proportional mortality curve: Prior to modelling the functional response, proportional mortality over prey density was analysed using polynomial regression. The focus of this analysis was to characterise the slope near the origin rather than to test for significance (Juliano 2001). A negative initial slope would indicate a Type II functional response, while a positive initial slope would indicate a Type III.

Construction of functional response model: Holling (1959) modelled the Type II functional response as:

$$
N_{\mathrm{e}}=\frac{a T N_{\mathrm{t}}}{1+a T_{\mathrm{h}} N_{\mathrm{t}}}
$$


where $T$ is proportion of time spent foraging (i.e. searching + handling prey) and $T_{\mathrm{h}}$ is handling time per prey. The model assumes negligible prey depletion, consistent with the experimental design of this study. To obtain a model for the Type III functional response, Hassell (1978) assumed a simple hyperbolic expression for the relationship between $a$ and $N_{\mathrm{t}}$. The functional response of sea stars was modelled using a modified version of Eq. (4) that incorporated a function characterising the form of the observed relationship between a (as calculated from the behavioural data) and $N_{\mathrm{t}}$.

Regression analysis of predation rate data: The modified functional response model was fit to predation rate data using weighted nonlinear least-squares regression, with the 4 replicates per scallop density treated as separate data points (Juliano \& Williams 1987, Bates \& Watts 1988). Regression weights were determined by fitting a quadratic function to the replication error variance. Based on behavioural observations, $T$ was fixed at 0.6 , and $T_{\mathrm{h}}$ at $0.035 \mathrm{~d}$ (no sediment) or $0.045 \mathrm{~d}$ (sediment). Standard deviations for parameter estimates and $90 \%$ confidence intervals for the fitted curves were calculated by bootstrapping (Huet et al. 1990).

Examination of behavioural mechanisms. To examine the behavioural biology underlying $a$, Pearson paired correlation-analyses were conducted to measure the strength of linear relationships between a (calculated from behavioural data) and its components $(E$, $T_{s}, \operatorname{Pr}\{\mathrm{A} \mid \mathrm{B}\}_{;}$Eqs. 1 to 3).

\section{RESULTS}

\section{Effects of prey density on sea star predation and behaviours}

Sea stars displayed a functional response when preying on sea scallops (Fig. 1a,b). Predation rate tended to be significantly greater at high prey densities than at low prey densities in both Expt 1 (Table 2) and Expt 2 (Table 3).

Proportional mortality would be expected to be highest at low prey densities for a Type II response, but highest at mid prey densities for a Type III response. In Expt 1, proportional mortality was affected by the interaction between prey density and substrate (Table 2, Fig. 1c,d). On sediment, proportional mortality tended to be higher in the mid-density range, consistent with expectations for a Type III functional response (Table 2; Fig. 1d). On no sediment, multiple comparisons were less clear, but were mostly consistent with a Type III response, particularly if considered alongside data from Expt 2 for very low prey densities (Table 2, Fig. 1c). In Expt 2, proportional mortality was very low and not significantly affected by prey density (Table 3, Fig. 1c).

The proportion of time that sea stars spent foraging was $0.57 \pm 0.02($ mean $\pm \mathrm{SE}, \mathrm{n}=104)$ (Figs. 2a,b \& 3a), and was not significantly affected by prey density or substrate in Expts 1 and 2 (Tables 2 \& 3). Moreover, the proportion of time spent searching was also unaffected by prey density or substrate in both experiments (Tables 2 \& 3). Handling time per prey was greater on sediment $(0.045 \pm 0.004 \mathrm{~d}, \mathrm{n}=47)$ than on no sediment $(0.035 \pm 0.003 d, n=59)$, but was not affected by prey density in Expt 1 (Table 2, Fig. 2c,d).

Observed encounter rate per search time increased with increasing prey density and was significantly greater on no sediment than on sediment (Tables $2 \& 3$, Figs. 2e,f \& 3b). Encounter rates calculated with the random movement model corresponded fairly well to observed rates (Figs. 2e,f \& 3b).
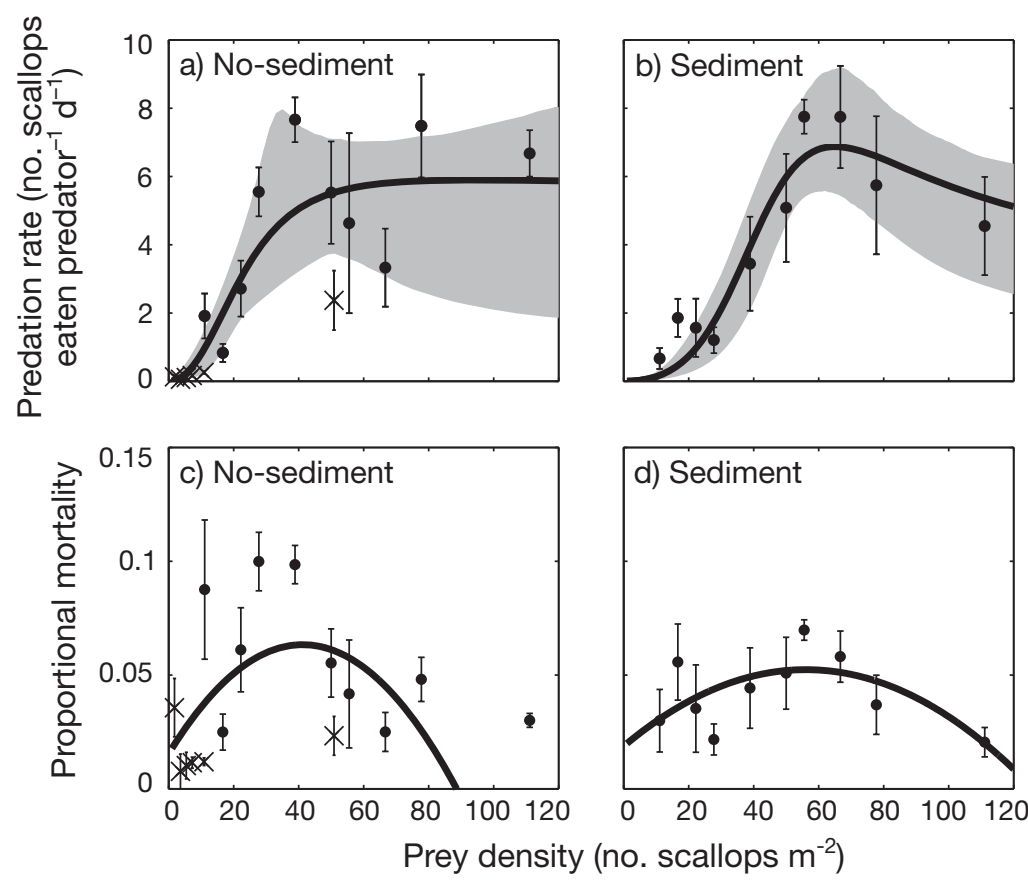

Fig. 1. Asterias vulgaris. Predation by sea stars on scallops Placopecten magellanicus in Expt $1(\bullet)$ and Expt $2(\mathrm{x})$. $(\mathrm{a}, \mathrm{b})$ Observed predation rate and estimated functional response model (regression line); parameter estimates (mean $\pm \mathrm{SD}$ ) for Eq. (5) are $b=81.32 \pm 198.8, c=-1.715 \pm 12.27$ and $d=0.0758 \pm 0.173$ for no sediment, and $b=606.6 \pm 578.0, c=-18.64 \pm 19.28$ and $d=0.186 \pm 0.161$ for sediment. Shading designates $90 \%$ confidence region. $(\mathrm{c}, \mathrm{d})$ Proportional mortality (means $\pm \mathrm{SE}_{;} \mathrm{n}=4$ ) of scallops and estimated polynomial regression model (line) 
Table 2. Asterias vulgaris. Statistical analyses of predation rate, proportional mortality and observed behaviour of sea stars preying on juvenile sea scallops Placopecten magellanicus in Expt 1. A full mixed-model ANOVA was used for predation rate (no. scallops $\mathrm{d}^{-1}$ ) and proportion of time spent foraging; a partial mixed-model ANOVA was used for encounter rate per search time (no. scallops $\mathrm{h}^{-1}$ ), and a fixed model ANOVA for proportional mortality and proportion of time spent searching (Winer et al. 1991, Wong \& Barbeau 2003). Predation rate could not be transformed to satisfy assumption of homoscedasticity, and raw data were used. Proportion of time spent searching was $\log ($ datum +1$)$-transformed. Handling time per prey (min) was analysed using a nested ANOVA; 2 densities (11 and 28 scallops $\mathrm{m}^{-2}$ ) were excluded from this analysis because of missing data. Significant $\mathrm{p}$-values are indicated in bold. Post hoc comparisons were done using SNK. Treatment-level means are listed in increasing magnitude; those sharing a common underline do not differ significantly. SV: Source of variation; D: prey density (no. $\mathrm{scallops}^{-2}$ ); $\mathrm{S} 1$ : no sediment; $\mathrm{S} 2$ : sediment; $\mathrm{df1}$ : numerator $\mathrm{df}$; df2: denominator df

\begin{tabular}{|c|c|c|c|c|c|c|}
\hline $\begin{array}{l}\text { Dependent } \\
\text { variable }\end{array}$ & SV & $\overline{\text { Effect }}$ & MS $\overline{\text { Error term }}$ & $F_{\mathrm{df} 1, \mathrm{df} 2}$ & $\mathrm{p}$ & Post hoc comparison \\
\hline Predation rate & $\begin{array}{c}\mathrm{D} \\
\mathrm{S} \\
\mathrm{D} \times \mathrm{S}\end{array}$ & $\begin{array}{l}33.83 \\
9.000 \\
16.24\end{array}$ & $\begin{array}{l}6.916 \\
2.875 \\
10.13\end{array}$ & $\begin{array}{l}4.89_{9,9} \\
3.13_{1,1} \\
1.60_{9,9}\end{array}$ & $\begin{array}{l}\mathbf{0 . 0 1 3} \\
0.328 \\
0.247\end{array}$ & D11 D17 D22 D28 D50 D67 D39 D111 D56 D78 \\
\hline $\begin{array}{l}\text { Proportional } \\
\text { mortality }\end{array}$ & $\begin{array}{l}\mathrm{D} \\
\mathrm{S} \\
\mathrm{D} \times \mathrm{S}\end{array}$ & $\begin{array}{l}0.001 \\
0.004 \\
0.003\end{array}$ & $\begin{array}{l}8.7 \times 10^{-4} \\
8.7 \times 10^{-4} \\
8.7 \times 10^{-4}\end{array}$ & $\begin{array}{l}1.56_{9,60} \\
5.12_{1,60} \\
3.55_{9,60}\end{array}$ & $\begin{array}{l}0.147 \\
0.027 \\
\mathbf{0 . 0 0 1}\end{array}$ & $\begin{array}{l}\text { S1: D17 D67 D111 D56 D78 D50 D22 D11 D39 D28 } \\
\text { S2: D111 D28 D11 D22 D78 D39 D50 D17 D67 D56 }\end{array}$ \\
\hline $\begin{array}{l}\text { Proportion time } \\
\text { spent foraging }\end{array}$ & $\begin{array}{c}\mathrm{D} \\
\mathrm{S} \\
\mathrm{D} \times \mathrm{S}\end{array}$ & $\begin{array}{c}0.070 \\
0.0007 \\
0.111\end{array}$ & $\begin{array}{c}0.031 \\
0.0008 \\
0.087\end{array}$ & $\begin{array}{l}2.21_{9,9} \\
0.90_{1,1} \\
1.26_{9,9}\end{array}$ & $\begin{array}{l}0.126 \\
0.516 \\
0.366\end{array}$ & \\
\hline $\begin{array}{l}\text { Proportion time } \\
\text { spent searching }\end{array}$ & $\begin{array}{c}\mathrm{D} \\
\mathrm{S} \\
\mathrm{D} \times \mathrm{S}\end{array}$ & $\begin{array}{l}0.002 \\
0.004 \\
0.002\end{array}$ & $\begin{array}{l}0.002 \\
0.002 \\
0.002\end{array}$ & $\begin{array}{l}1.28_{9,60} \\
2.34_{1,60} \\
0.92_{9,60}\end{array}$ & $\begin{array}{l}0.265 \\
0.131 \\
0.514\end{array}$ & \\
\hline $\begin{array}{l}\text { Handling time } \\
\text { prey }^{-1}\end{array}$ & $\begin{array}{c}\mathrm{D} \\
\mathrm{S} \\
\mathrm{D} \times \mathrm{S}\end{array}$ & $\begin{array}{l}1241 \\
8672 \\
3027\end{array}$ & $\begin{array}{l}1685 \\
1685 \\
1685\end{array}$ & $\begin{array}{l}0.74_{7,32} \\
5.15_{1,32} \\
1.80_{7,32}\end{array}$ & $\begin{array}{l}0.643 \\
\mathbf{0 . 0 3 0} \\
0.122\end{array}$ & \\
\hline $\begin{array}{l}\text { Encounter rate } \\
\text { search time }^{-1}\end{array}$ & $\begin{array}{c}\mathrm{D} \\
\mathrm{S} \\
\mathrm{D} \times \mathrm{S}\end{array}$ & $\begin{array}{l}106.0 \\
195.1 \\
11.62\end{array}$ & $\begin{array}{l}18.32 \\
7.100 \\
7.100\end{array}$ & $\begin{array}{c}5.79_{9,9} \\
27.47_{1,47} \\
1.64_{9,47}\end{array}$ & $\begin{array}{c}\mathbf{0 . 0 0 8} \\
<\mathbf{0 . 0 0 1} \\
0.132\end{array}$ & D11 D22 D17 D28 D50 D39 D56 D111 D78 D67 \\
\hline
\end{tabular}

Table 3. Asterias vulgaris. Statistical analyses of predation rate, proportional mortality and observed behaviour of sea stars preying on juvenile sea scallops Placopecten magellanicus in Expt 2. Predation rate (no. scallops $\mathrm{d}^{-1}$ ) could not be transformed to satisfy assumption of homoscedasticity, and raw data were used. Encounter rate per search time (no. scallops $\mathrm{h}^{-1}$ ) was square-root-transformed. Significant $\mathrm{p}$-values are indicated in bold. Post hoc comparisons were done using Ryan's $Q$-test. Treatment level means are listed in increasing magnitude; those sharing a common underline do not differ significantly. SV: Source of variation;

D: Prey density (no. scallops $\mathrm{m}^{-2}$ ), df1: numerator $\mathrm{df}_{\text {; }} \mathrm{df2}$ : denominator

\begin{tabular}{|c|c|c|c|c|c|c|}
\hline \multirow{2}{*}{$\begin{array}{l}\text { Dependent } \\
\text { variable }\end{array}$} & \multirow[t]{2}{*}{ SV } & \multicolumn{2}{|c|}{ MS } & \multirow[t]{2}{*}{$F_{\mathrm{df} 1, \mathrm{df} 2}$} & \multirow[t]{2}{*}{$\mathrm{p}$} & \multirow[t]{2}{*}{ Post hoc comparison } \\
\hline & & Effect & Error term & & & \\
\hline Predation rate & $\mathrm{D}$ & 3.321 & 0.513 & $6.47_{5,18}$ & 0.001 & $\underline{\text { D4 D5 D2 D7 D11 D56 }}$ \\
\hline $\begin{array}{l}\text { Proportional } \\
\text { mortality }\end{array}$ & $\mathrm{D}$ & $4.6 \times 10^{-4}$ & $2.2 \times 10^{-4}$ & $2.04_{5,18}$ & 0.121 & \\
\hline Proportion time & & & & & & \\
\hline spent foraging & $\mathrm{D}$ & 0.075 & 0.037 & $2.03_{5,18}$ & 0.123 & \\
\hline spent searching & $\mathrm{D}$ & 0.062 & 0.034 & $1.82_{5,18}$ & 0.160 & \\
\hline $\begin{array}{l}\text { Encounter rate } \\
\text { search time }{ }^{-1}\end{array}$ & $\mathrm{D}$ & 10.79 & 0.422 & $25.6_{5,18}$ & $<0.001$ & D2 D4 D7 D5 D11 D56 \\
\hline
\end{tabular}

\section{Fitting of functional response model to predation rate data}

Proportional mortality curve

The initial slope of the polynomial regression curve for proportional mortality was positive for both no sediment $(y=0.015+0.002 x$ $\left.-2.8 \cdot 10^{-5} x^{2}, p<0.05\right)$ and sediment $\left(y=0.019+0.0012 x-1.1 \cdot 10^{-5} x^{2}, p<\right.$ $0.1)$, consistent with a Type III functional response (Fig. 1c,d). This was also supported by the ANOVA results (see above).

Construction of functional response model

In contrast to handling time per prey, a (calculated from behavioural 

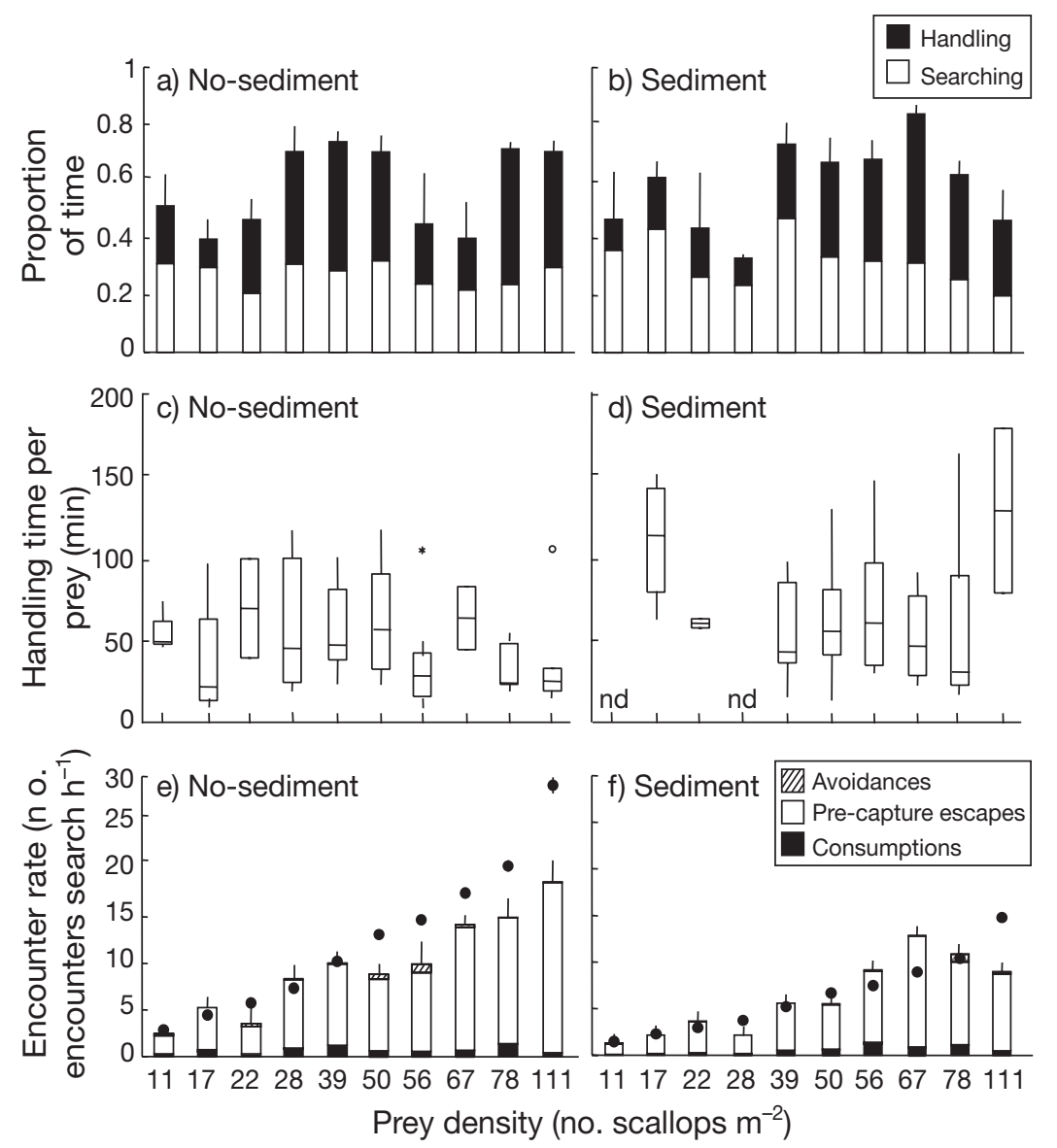

Fig. 2. Asterias vulgaris. Behaviour of sea stars preying on scallops Placopecten magellanicus in Expt 1. $(\mathrm{a}, \mathrm{b})$ Mean $(+1 \mathrm{SE}, \mathrm{n}=4)$ proportion of time spent foraging (i.e. searching for and handling prey); remainder of time was spent inactive or moving but not foraging. $(\mathrm{c}, \mathrm{d})$ Box-plots of handling time per prey; nd: no data. (e,f) Mean (+ $1 \mathrm{SE}, \mathrm{n}=3$ or 4 ) encounters per predator search time, as predicted by random movement $(\bullet)$ and as observed (histogram bars). Shading indicates relative occurrences of 3 possible outcomes of an encounter (order in key follows order in bars). Additionally, a few post-capture escapes were observed at 17, 28, 67 and 78 scallops $\mathrm{m}^{-2}$ (e) and 28, 39, 50, 56, 67 and 78 scallops $\mathrm{m}^{-2}$ (f), and ranged from 0.056 to 0.267 post-capture escapes search $\mathrm{h}^{-1}$ data) was density-dependent; it increased at low prey densities and decreased at high prey densities (Fig. 4). The hyperbolic function assumed by Hassell (1978) for a Type III model is clearly not appropriate in this case. Instead, the observed relationship between $a$ and $N_{\mathrm{t}}$ was better described by the inverse quadratic function:

$$
a=\frac{N_{\mathrm{t}}}{b+c N_{\mathrm{t}}+d N_{\mathrm{t}}^{2}}
$$

where $b, c$ and $d$ are unknown parameters. The Type II functional response model Eq. (4) was modified by substituting Eq. (5) for a. Note that this modified functional response model is more general than the model traditionally used for the Type III functional response (i.e. when $d=0$; Hassell 1978), and will support a variety of functions. For example, this model supports decreases in predation rate at high prey density.

Regression analysis of predation rate data

The modified functional response model was fit to the predation-rate data and described a curve resembling a Type III functional response on both substrates (Fig. 1a,b). The regressions for no sediment $\left(F_{3,60}=18.3, \mathrm{p}<0.001\right)$ and sediment $\left(F_{3,36}=18.7, \mathrm{p}<0.001\right)$ explained 48 and $61 \%$, respectively, of the total

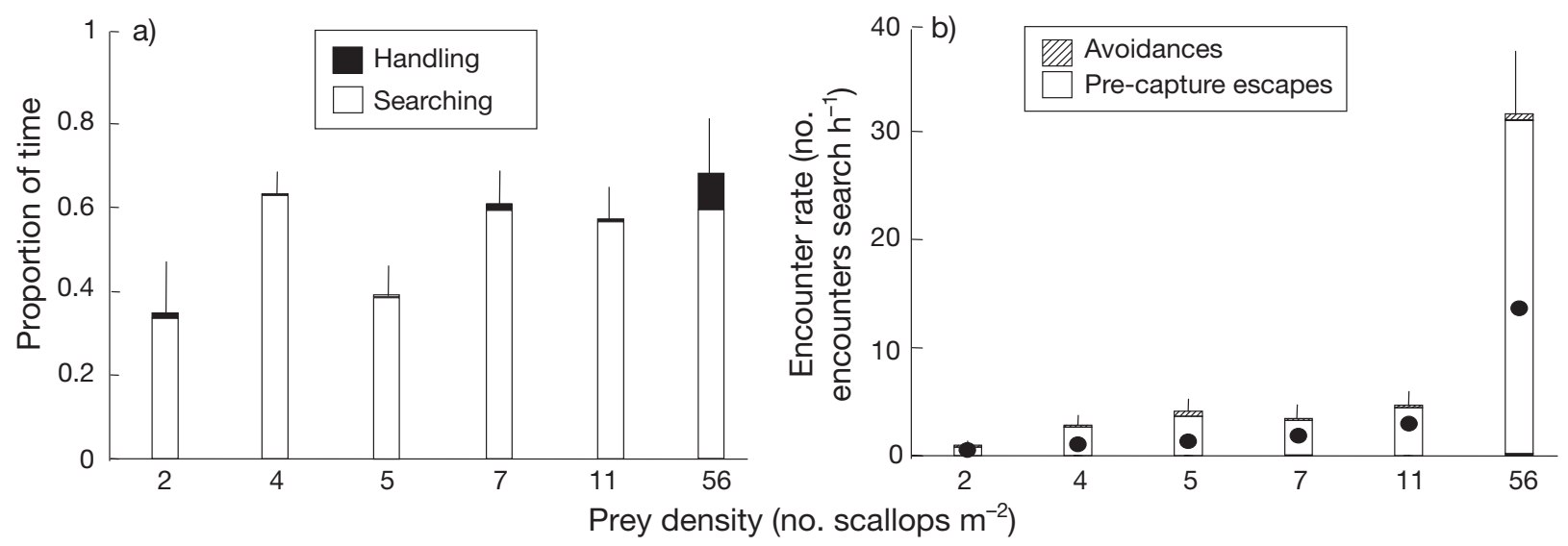

Fig. 3. Asterias vulgaris. Behaviour of sea stars preying on juvenile sea scallops Placopecten magellanicus in Expt 2. (a) Mean (+ $1 \mathrm{SD}, \mathrm{n}=4)$ proportion of time spent foraging. (b) Mean (+ $1 \mathrm{SD}, \mathrm{n}=4)$ encounters per predator search time, as predicted by random movement $(\bullet)$ and as observed (histogram bars). Further details as in Fig. 2. A few consumptions were observed at 7 and 56 scallops $\mathrm{m}^{-2}$ and were 0.054 and 0.231 consumptions search $\mathrm{h}^{-1}$, respectively 
variance about the mean, although these statistics are calculated assuming asymptotic normality and are not entirely appropriate for non-linear regression (Draper \& Smith 1998). The predation rate data generally fell within the calculated confidence intervals, supporting the models as plausible fits. The resulting functional response curves differed between sediments. On sediment, predation rate was density dependent over a larger range of prey densities than on no sediment (Fig. 1a,b). Also, at high prey density, the predation rate tended to decrease on sediment, while it approached a plateau on no sediment.

The estimates of a obtained from fitting the functional response model to predation data (calculated by substituting estimated values of $b, c, d$ [Fig. 1] into Eq. 5) corresponded well to estimates of a derived from mechanistic analysis of the behavioural data (calculated with Eq. 3) (Fig. 4a,b). On no sediment, the initial increase in a was shorter than on sediment.

\section{Examination of behavioural mechanisms}

The Pr\{consumption|encounter\} was strongly correlated with $a$, as calculated from behavioural data $\left(\mathrm{r}_{36}=0.998\right.$ and $\mathrm{r}_{22}=0.999$ for no sediment, Expts 1 and 2 , respectively, and $r_{36}=0.997$ for sediment, p $<0.05$; Fig. 5a). This correlation appeared to be driven (see Fig. 5) by the strong correlation of $\operatorname{Pr}$ \{capture|attack\} with a $\left(r_{35}=0.962\right.$ and $r_{21}=0.999$ for no sediment, Expts 1 and 2, respectively, and $r_{36}=0.839$ for sediment, $p<0.05$ ). The other behavioural components of a $\left(E, T_{\mathrm{s}}\right.$ Pr\{attack|encounter $\}$, and $\operatorname{Pr}$ (consumption|capture\}) were not correlated with a ( $\mathrm{r}_{21}$ to $36=-0.249$ to 0.339 , p > 0.05) (Figs. 2, $3 \& 5$ ).

\section{DISCUSSION}

The functional response is an important ecological process that depends on the relationship between various predator-prey behaviours and prey

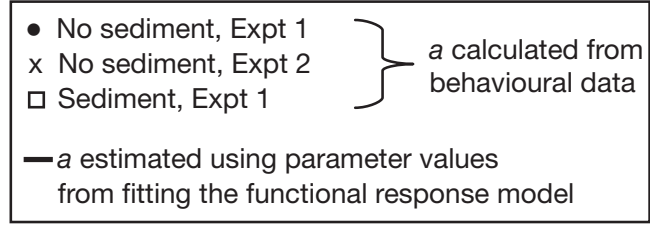

a) No sediment

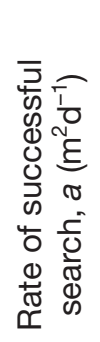

1
0.75
0.25 b) Sediment

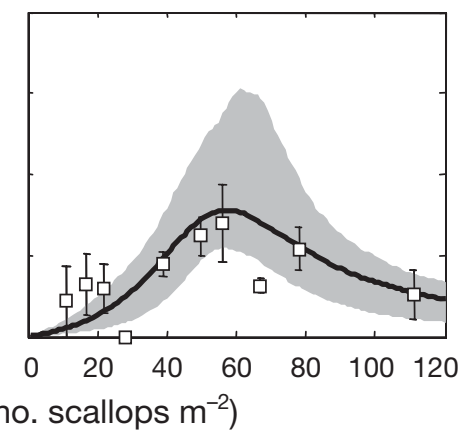

Fig. 4. Asterias vulgaris. Comparison of rate of successful search a obtained from 2 different sources: calculated from behavioural data (mean \pm SE) (Eq. 3) and estimated using parameter values obtained by fitting the functional response model to predation rate data (Eq. 5 \& Fig. 1). Shading designates $90 \%$ confidence region of a estimated from fitting the functional response model
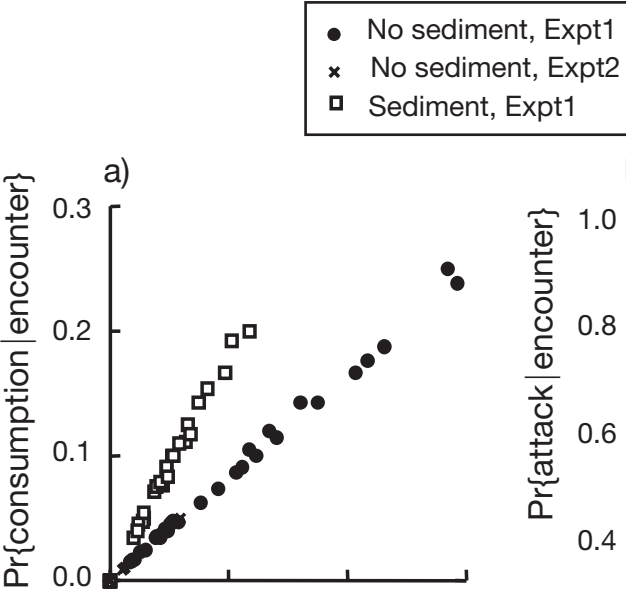

b)

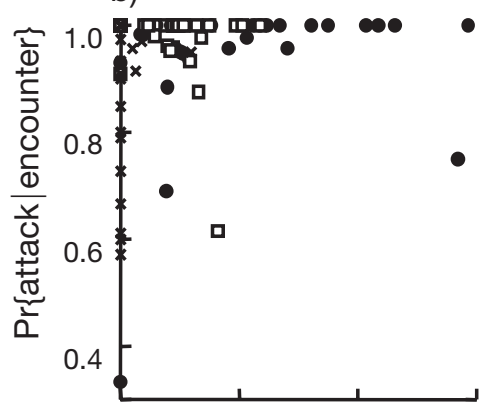

c)

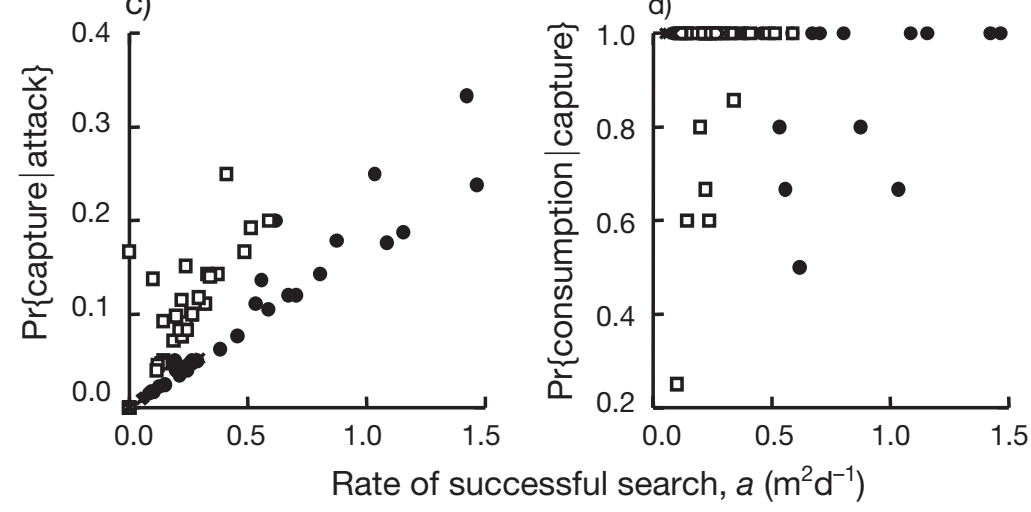

Fig. 5. Asterias vulgaris. Correlations between rate of successful search (a) and some of its behavioural components 
density. These behaviours are incorporated into the 2 parameters that characterise the functional response, $a$ and $T_{\mathrm{h}}$. Despite the importance of these parameters, most functional response studies only obtain estimates using curve-fitting procedures. Estimates of parameter values obtained by this approach do not reveal how the parameters and their behavioural components change with changing prey density, and contribute little to understanding the mechanisms driving functional responses. In this study, we used behavioural data from laboratory experiments to better understand the connection between the parameters of the functional response model and the actual behaviour of predators and prey.

In ecological theory, it is recognised that there are several distinct types of functional response, reflecting different possibilities for changes in predator-prey behaviour. In practice however, it is often challenging to identify the functional response displayed in a particular system. In several studies, ANOVAs with proportional mortality have been employed (Lipcius \& Hines 1986, Eggleston 1990a, Sponaugle \& Lawton 1990). However, high inherent variability between individuals (as in this study; see also Eggleston 1990b, Fritz et al. 2001, Juliano 2001) often makes it difficult for post-hoc comparisons to locate differences. Other studies have used logistic regression of proportional mortality and prey density (Trexler et al. 1988, Juliano 2001), but many data sets (such as ours) do not easily fit into this framework. In our study, a comprehensive method of identifying functional responses was developed by using a combination of modelling, investigations of proportional mortality, and observations of behaviour.

Using the combination of analyses, sea stars on both substrates were found to have a functional response resembling a Type III. This is consistent with a recent field experiment using tethered scallops that suggested that sea stars had a Type III functional response when foraging on a heterogeneous substrate consisting of cobbles, gravel and shells embedded in a silt matrix (Wong et al. 2005). In an earlier field study on a similar sea bottom (Barbeau et al. 1994, 1998), a Type I functional response had been observed for sea stars preying on juvenile scallops; however, we suspect that the small range of prey density used did not allow full characterisation of the functional response. In our current laboratory experiments, substrate did not change the type of response (e.g. from a hyperbolic function to a sigmoid function as in Lipcius \& Hines 1986), although some aspects of the response differed between substrates. For example, predation rate on the heterogeneous substrate (i.e. sediment) was positively density-dependent over a wider range of prey densities (Fig. 1), providing a larger refuge for prey at low density than on the homogeneous, hard substrate (i.e., no sediment). This did not result from prey using the sediment to avoid predators, since scallops do not borrow into sediment or use crevices between sediment particles to hide from predators (Wong \& Barbeau 2003). Instead, slower movement velocities of sea stars resulting in lower encounter rates with scallops and longer prey-handling times on the heterogeneous than on the homogeneous substrate, coupled with changes in the probability of capture upon attack, probably played an important role (discussed in detail below). Additionally, the functional response differed between substrates since predation rate on sediment decreased at high prey density (Fig. 1). A decrease at high prey density is one of the features of the less-commonly described Type IV functional response, which may occur when predator foraging is disrupted by conflicting prey stimuli (Taylor 1984). In the current study, residual chemical cues from prey may have been retained by sediment particles, causing confusion for predators at high prey densities (Sponaugle \& Lawton 1990). Consequently, sea stars on sediment had a modified Type III functional response, with a decrease in predation rate at high prey density. Based on our comparison between no sediment and sediment treatment levels, substrate heterogeneity appears to influence certain aspects of density-dependent predation.

The functional response models we fit to observed predation data were refined by using behavioural data to describe the relationship between prey density and behavioural parameters. $T_{\mathrm{h}}$ was constant over prey density, while a increased at low prey densities and then decreased at high prey densities. The inverse quadratic used to describe the relationship between $a$ and $N_{\mathrm{t}}$ allows flexibility in the shape of a over prey density. This supports different types of functional responses, such as the modified Type III functional response we observed on sediment. Most importantly, our refined functional response model was consistent with the underlying behavioural biology of the sea star-scallop system. The relationship described between prey density and a has not been previously observed (except indirectly, by Hassell et al. 1977). To our knowledge, the only other comprehensive attempt to calculate a using direct behavioural observations was by Streams (1994), who found a and its components (encounter, attack, capture) to be constant across all prey densities for nymphs Notonecta undulata feeding on conspecific prey.

By using a mechanistic framework for analysing observed behaviour, a was directly related to specific behaviours that occur when a predator encounters, attacks, captures and consumes a prey. Estimates of $a$ calculated from this behavioural analysis were concordant with estimates of a obtained from regression 
analysis. This was encouraging, given that the estimates of a being compared were determined using 2 different approaches. The behavioural estimates of $a$ were derived from sampled observations of predator and prey behaviour, while the regression estimates were derived from recorded predation rates (simply the numbers of scallops consumed). Thus, the match between the behavioural and regression analyses offers a validation for the characterisation of both $a$ and the functional response.

In our study, the mechanistic approach was useful to explain how particular behaviours of the predator and prey led to the observed functional response. More precisely, the characterisation of different behaviours made it possible to identify a likely mechanism for explaining the observed relationship between prey density and $a$. The probability of capture upon attack strongly co-varied with $a$, being higher at intermediate prey densities than at low or high prey densities (Fig. 5, see also Wong 2004). In contrast, the probability of attack upon encounter and the probability of consumption upon capture did not vary with $a$, being consistently high across all prey densities (Fig. 5, see also Wong 2004). Thus, it appears that the most likely mechanism underlying the observed functional response was that sea stars at intermediate prey densities were more effective at capturing attacked scallops than were sea stars at low or high prey densities. At higher prey densities, it may be that the ability to capture a scallop was hampered by conflicting stimuli emanating from several nearby scallops. At lower prey densities, sea stars encountered scallops less frequently and, as a result, were perhaps less practiced at capturing their prey. Other behaviours which have been suggested to explain a Type III functional response were found to not vary with prey density in our experiments. These included handling time per prey and proportion of time spent searching (Hassell 1978, Abrams 1990, Streams 1994). Encounter rate did increase with prey density, but increased in a manner consistent with a model of random movement (Figs. 2 \& 3 ), indicating that the observed response did not result from an increase in predator movement velocity with increased prey density.

A conceptual model has recently been proposed by Seitz et al. (2001) that relates antipredator adaptations of prey (armour versus locomotion: Vermeij 1987) to the type of functional response expected from predators. Based on a review of several studies characterising functional responses on bivalve molluscs (Seitz et al. 2001), it appears that Type II functional responses are often observed with prey species using an armour defence strategy (such as a thick shell). This strategy would increase the relative importance of handling time compared to other components of predation (such as encounter rate or probability of capture upon attack). If prey species using such a strategy are solitary or without habitat refuge, then they would be more likely to experience an inversely density-dependent (Type II) functional response. In contrast, Type III functional responses are apparently often observed with prey species using a locomotion-related defence strategy (such as burrowing or swimming). This strategy would increase the importance of evasion components (encounter rate or probability of capture upon attack) relative to handling time in the predator-prey interaction. At low prey density, predator foragingefficiency on prey species using such a strategy would be reduced, and so predators would display a densitydependent (Type III) functional response. Certainly, given the locomotory defence strategy used by juvenile scallops against sea stars (i.e., an effective swimming escape response upon attack), our study is consistent with the conceptual model (since we detected a Type III functional response). However, based on our detailed examination of the specific behaviours underlying the functional response, we conclude that it is not the differential emphasis of handling time versus locomotion-related predation components that determines a Type II or III response. Rather, the type of functional response is determined by whether or not the behavioural component in question (handling time, probability of encounter or probability of capture upon attack) changes as a function of prey density. If the behavioural component does not change, then a Type II response is expected. If the behavioural component does change, then a more complex functional response is expected. Nevertheless, it may be that in predatorprey systems in which handling time is emphasised over other behavioural components, the various behavioural components are less likely to change with changing prey density (and this would lead to observations of Type II responses) than in systems emphasising predation components related to prey locomotion.

Our study was successful in using predator and prey behaviour to better understand observed functional responses. This success depended partly on having accurate characterisations of the various behavioural components in the functional response model. For instance, the quantification of $T_{\mathrm{h}}$ included digestion time. This is because a sea star cannot begin searching for other prey until it has completed the external digestion and absorption of each scallop's contents. The omission of digestion time is often cited as an explanation for why regression estimates do not conform to behavioural measures (Hassell 1978). Also, the quantification of $T$ included only the proportion of time spent foraging (searching + handling). Most studies have instead quantified $T$ as the total time available for foraging, which includes periods of non-foraging (e.g. 
Hassell et al. 1977, Lipcius \& Hines 1986, Eggleston 1990a) and, as a consequence, regression estimates would be less likely to match behavioural observations.

In conclusion, particular predator-prey behaviours (i.e. encounter rate per search time, Pr\{consumption | encounter\}, proportion of time spent searching, handling time per prey) are important mechanisms that underlie the functional response. These behaviours, and in particular the components related to $a_{\text {, }}$ are useful for identifying and understanding the observed functional response. Using data from a simple marine invertebrate predator-prey system, this study directly links behavioural information to observed patterns of predation. A general advantage of the mechanistic approach used is that it provides a useful modelling framework for linking specific behaviours of individuals to population-level processes (cf. Barbeau \& Caswell 1999).

Acknowledgements. We thank L. Wright and T. James for technical support, and S. Heard, B. MacDonald, S. Robinson and an anonymous reviewer for useful comments. M.C.W. was supported by a Natural Sciences and Engineering Research Council of Canada (NSERC) Post-Graduate Scholarship, funding from the Network of Centres of Excellence for Mathematics of Information Technology and Complex Systems (MITACS), a Vaughan Graduate Fellowship in Marine Science, and a Frazee Graduate Scholarship in Marine Studies. M.D. was supported by a NSERC Discovery Grant. Research was funded by a NSERC Discovery Grant to M.A.B., and a Huntsman Marine Science Centre Graduate Student Research Grant to M.C.W.

\section{LITERATURE CITED}

Abrams PA (1990) The effects of adaptive behaviour on the type-2 functional response. Ecology 71:877-885

Barbeau MA, Caswell H (1999) A matrix model for short-term dynamics of seeded populations of sea scallops. Ecol Appl 9:266-287

Barbeau MA, Scheibling RE (1994) Behavioural mechanisms of prey size selection by sea stars (Asterias vulgaris Verrill) and crabs (Cancer irroratus Say) preying on juvenile sea scallops (Placopecten magellanicus Gmelin). J Exp Mar Biol Ecol 180:103-136

Barbeau MA, Scheibling RE, Hatcher BG, Taylor LH, Hennigar AW (1994) Survival analysis of tethered juvenile sea scallops Placopecten magellanicus in field experiments: effects of predators, scallop size and density, site and season. Mar Ecol Prog Ser 115:243-256

Barbeau MA, Scheibling RE, Hatcher BG (1998) Behavioural responses of predatory crabs and sea stars to varying density of juvenile sea scallops. Aquaculture 169:87-98

Bates DM, Watts DG (1988) Nonlinear regression analysis and its applications. John Wiley \& Sons, New York

Beninger PG, le Pennec M (1991) Funtional anatomy of scallops. In: Shumway SE (ed) Scallops: biology, ecology, and aquaculture. Elsevier, Amsterdam, p 133-233

Cliche G, Giguère M, Vigneau S (1994) Dispersal and mortality of sea scallops, Placopecten magellanicus (Gmelin,
1791), seeded on the sea bottom off Îles-de-la-Madeleine. J Shellfish Res 13:565-570

Dadswell MJ, Weihs D (1990) Size-related hydrodynamic characteristics of the giant scallops, Placopecten magellanicus (Bivalvia: Pectinidae). Can J Zool 68:778-785

Day RW, Quinn GP (1989) Comparisons of treatments after an analysis of variance in ecology. Ecol Monogr 59:433-463

Draper NR, Smith H (1998) Applied regression analysis. John Wiley \& Sons, New York

Eggleston DB (1990a) Foraging behaviour of the blue crab, Callinectes sapidus, on juvenile oysters, Crassostrea virginica: effects of prey density and size. Bull Mar Sci 46: 62-82

Eggleston DB (1990b) Behavioural mechanisms underlying variable functional responses of blue crabs, Callinectes sapidus feeding on juvenile oysters, Crassostrea virginica. J Anim Ecol 59:651-630

Fritz H, Durant D, Guillemain M (2001) Shape and sources of variations of the functional response of wildfowl: an experiment with mallards, Anas platyrhynchos. Oikos 93: 488-496

Gross T, Ebenhöh W, Feudel U (2004) Enrichment and foodchain stability: the impact of different forms of predator-prey interactions. J Theor Biol 227:349-358

Hassell MP (1978) The dynamics of arthropod predator-prey systems. Princeton University Press, Princeton, NJ

Hassell MP, Lawton JH, Beddington JR (1976) The components of arthropod predation I. The prey death-rate. J Anim Ecol 45:135-164

Hassell MP, Lawton JH, Beddington JR (1977) Sigmoid functional responses by invertebrate predators and parasitoids. J Anim Ecol 46:249-262

Hatcher BG, Scheibling RE, Barbeau MA, Hennigar AW, Taylor LH, Windust A (1996) Dispersion and mortality of a population of sea scallop (Placopecten magellanicus) seeded in a tidal channel. Can J Fish Aquat Sci 53:38-54

Himmelman JH, Dutil C (1991) Distribution, population structure and feeding of subtidal seastars in the northern Gulf of St. Lawrence. Mar Ecol Prog Ser 76:61-72

Hollett J, Dabinett PE (1989) Effect of ration on growth and growth efficiency of spat of the giant scallop, Placopecten magellanicus (Gmelin). Bull Aqua Assoc Can 89:71-73

Holling CS (1959) Some characteristics of simple types of predation and parasitism. Can Entomol 91:385-398

Holling CS (1966) The functional response of invertebrate predators to prey density. Mem Entomol Soc Can 48:1-87

Huet SE, Jolivet E, Messean A (1990) Some simulation results about confidence intervals and bootstrap methods in nonlinear regression. Statistics 21:369-432

Juliano SA (2001) Nonlinear curve fitting. In: Scheiner SM, Gurevitch J (eds) Design and analysis of ecological experiments. Oxford University Press, New York p 178-196

Juliano SA, Williams FM (1987) A comparison of methods for estimating the functional response parameters of the random predator equation. J Anim Ecol 56:641-653

Land MF (1984) Molluscs. In: Ali MA (ed) Photoreception and vision in invertebrates. Plenum Press, New York, p 699-725

Lipcius RN, Hines AH (1986) Variable functional responses of a marine predator in dissimilar homogeneous microhabitats. Ecology 67:1361-1371

Manuel JL, Dadswell MJ (1993) Swimming of juvenile sea scallops, Placopecten magellanicus (Gmelin): a minimum size for effective swimming? J Exp Mar Biol Ecol 174: 137-175

O'Brien WJ (1979) The predator-prey interaction of planktivorous fish and zooplankton. Am Sci 67:572-581 
Seitz RD, Lipcius RN, Hines AH, Eggleston DB (2001) Density-dependent predation, habitat variation, and the persistence of marine bivalve prey. Ecology 82:2435-2451

Sloan NA (1980) Aspects of the feeding biology of asteroids. Oceanogr Mar Biol Annu Rev 18:57-124

Solomon ME (1949) The natural control of animal populations. J Anim Ecol 18:1-35

Spitze K (1985) Functional response of an ambush predator: Chaoborus americanus predation on Daphnia pulex. Ecology 66:938-949

Sponaugle S, Lawton P (1990) Portunid crab predation on juvenile hard clams: effects of substrate type and prey density. Mar Ecol Prog Ser 67:43-53

Stokesbury KDE, Himmelman JH (1995) Biological and physical variables associated with aggregations of the giant scallop Placopecten magellanicus. Can J Fish Aquat Sci 52:743-753

Streams FA (1994) Effect of prey size on attack components of the functional response by Notonecta undulata. Oecologia 98:57-63

Taylor RJ (1984) Predation. Chapman \& Hall, New York

Trexler JC, McCulloch CE, Travis J (1988) How can the functional response best be determined? Oecologia 76: 206-214

Turchin P (2003) Complex population dynamics: a theoretical/empirical synthesis. Princeton University Press, Princeton, NJ

Editorial responsibility: Roger N. Hughes (Contributing Editor), Bangor, UK
Underwood AJ (1997) Experiments in ecology. Cambridge University Press, Cambridge

Vermeij GJ (1987) Evolution and escalation. Princeton University Press, Princeton, NJ

Wentworth CK (1922) A scale of grade and class terms for clastic sediments. J Geol 30:377-392

Winer BJ, Brown DR, Michels KM (1991) Statistical principles in experimental design. McGraw-Hill, New York

Wong MC (2004) Predation and its underlying behavioural mechanisms in a marine benthic invertebrate system. $\mathrm{PhD}$ dissertation, University of New Brunswick, Fredericton, Canada

Wong MC, Barbeau MA (2003) Effects of substrate on interactions between juvenile sea scallops (Placopecten magellanicus (Gmelin)) and predatory sea stars (Asterias vulgaris Verrill) and rock crabs (Cancer irroratus Say). J Exp Mar Biol Ecol 287:155-178

Wong MC, Barbeau MA (2005) Prey selection and the functional response of sea stars (Asterias vulgaris Verrill) and rock crabs (Cancer irroratus Say) preying on juvenile sea scallops (Placopecten magellanicus (Gmelin)) and blue mussels (Mytilus edulis Linnaeus). J Exp Mar Biol Ecol 327:1-12

Wong MC, Barbeau MA, Hennigar AW, Robinson SMC (2005) Protective refuges for seeded juvenile scallops (Placopecten magellanicus) from sea star (Asterias spp.) and crab (Cancer irroratus and Carcinus maenas) predation. Can J Fish Aquat Sci 62:1766-1781

Submitted: May 9, 2005; Accepted: November 23, 2005 Proofs received from author(s): June 23, 2006 